\title{
Brexit and skill shortages: An empirical analysis of UK SMEs
}

\author{
Pattanapong Tiwasing* \\ Coventry University, $U K$
}

Received: 25 November 2019

Revised: 8 April 2020

Accepted: 4 May 2020

\begin{abstract}
This paper examines the perspectives of SMEs on Brexit and skill shortages using crosssectional data of 2,969 SMEs from a UK Government's Small Business survey for 2016. The logistic regression with clustered standard errors is applied to analyse the association between SMEs considering Brexit as a major business obstacle and the probability of SMEs identifying skill shortages in their businesses. The results show that firms with a shortage of managerial skills/expertise have a $6.5 \%$ higher probability to report that Brexit will affect their businesses, followed by difficulties in staff recruitment $(4.5 \%)$ and shortage of skills within external labour markets $(3.8 \%)$. Policy recommendations are provided.
\end{abstract}

Keywords: Brexit; skill shortages; SMEs; United Kingdom

JEL Classification Codes: C00, C21, C40

\section{Introduction}

In June 2016 the UK voted to leave the European Union (EU) (Brexit). This will lead to a dramatic change in the rules governing how UK firms operate their businesses both domestically and internationally. A significant consequence is a shortage of skills. According to the Edge Foundation's report (2018), more than 40\% of employers struggle to recruit the highly skilled labour required for their businesses. The Office for National Statistics (ONS) (2018) also reports that the post referendum net migration from the EU, which is a main source of labour supply, has fallen by $5.5 \%$ in 2017 . Thus, Brexit is likely to add to the pressures of existing skills gaps since the UK Government's stated intention is likely to end the free movement of labour.

Brexit is undoubtedly the most controversial issue related to immigration, trading, and future growth. It is viewed as a major obstacle for large firms and particular industries such as manufacturing and financial services (Brown et al., 2019), while SMEs have been overlooked.

\footnotetext{
* Corresponding author. E-mail: pattanapong.tiwasing@ coventry.ac.uk.

Citation: Tiwasing, P. (2021) Brexit and skill shortages: An empirical analysis of UK SMEs, Economics and Business Letters, 10(1), 9-15.
}

DOI: 10.17811/ebl.10.1.2021.9-15 
SMEs play a vital role in the UK economy, accounting for $52 \%$ of total revenue and $60 \%$ of total UK employment (BEIS, 2018). Nearly $20 \%$ of all SMEs operate in the construction and manufacturing sectors (BEIS, 2018) where the majority of the labour force in these sectors is from EU countries (McCollum and Findlay, 2015). Miller (2016) also mentions that London (urban dominance) also relies on low-cost sources of EU labour such as construction workers. However, skill shortages are not only limited to the low-skilled sectors, but also distribute across the medium- and high-skilled sectors. For example, the Federation of Small Businesses (FBS) (2017) reports that the most skills shortage vacancy reported by SMEs is skilled trades with $37 \%$, followed by professionals (23\%) and information and communication (15\%). Also, the Edge Foundation (2019) reveals that more than 100,000 jobs are reported as shortage vacancies in the hospitality industry which are mainly characterised as hard-to-fill vacancies. According to these issues, Brown et al. (2019) suggest that employing EU migrants can help UK SMEs to overcome labour shortages, especially in growth-oriented and high-skilled businesses. Therefore, a Brexit-induced immigration reduction could have dire consequences in access to appropriate labour inputs, which may affect the wider economy (Portes and Forte, 2017).

Even at this stage it is important to envisage the likely effects of Brexit on labour skill shortages. This study, therefore, aims to examine the perspectives of SMEs on Brexit and skill shortages to provide an evidence-based analysis to debates regarding the potential impact of Brexit on skill shortages during the interim situation after Brexit. This study uses large crosssectional data of 9,243 UK SMEs from the Longitudinal Small Business Survey (LSBS) for 2016 commissioned by the Department for Business, Energy and Industrial Strategy (BEIS), especially focusing on 2,969 SMEs who report skill shortages and difficulty in recruiting staff. To investigate the relationship between SMEs considering whether Brexit is a major obstacle and firms reporting skill shortages as well as other key business profiles, Logistic regression with clustered standard errors is applied to account for heteroscedasticity across the four UK nations in the analysis. The key findings reveal that SMEs with shortage of skills in managerial skills and expertise, skills within the external labour market, and staff recruitment are more likely to identify that Brexit will affect their businesses. This suggests that new immigration policy requires substantial recalibration to ensure that Brexit will not add more pressure to the current and future situation of skill shortages for SMEs.

This paper is organised as follows. Section 2 discusses methodology. Section 3 details secondary data and descriptive statistics. Empirical results are provided in Section 4. Section 5 concludes with recommendations.

\section{Methodology}

Brexit can potentially affect the UK SMEs, especially for those who are currently facing skill shortages if they will no longer have access to the EU labour market. They may find this situation even more difficult to recruit skilled workers. To examine the potential relationship between Brexit and skill shortages, in the LSBS 2016 firms were asked whether they identify Brexit as a major business obstacle. Also, firms were asked whether their businesses have been affected by different types of recruitment and skills: difficulty in recruiting staff, shortage of managerial skills/expertise, shortage of skills within the external labour market, and shortage of skills within the existing workplace. To estimate the association between a firm identifying Brexit as a major obstacle and the probability of a firm reporting skilled labour shortages as well as other key determinants, logistic regression is therefore applied since the dependent variable (Brexit) is a binary variable, where: 


$$
\text { Brexit }= \begin{cases}1, & \text { if a firm identifies Brexit as a major business obstacle } \\ 0, & \text { otherwise }\end{cases}
$$

Thus, the probability function of a firm utilised for the logistic regression is:

$$
\operatorname{Pr}\left(\text { Brexit }_{\mathrm{i}}=1 \mid \mathbf{X}_{\mathrm{i}}\right)=f\left(\beta_{0}+\boldsymbol{\beta}_{1 \mathrm{i}} \mathbf{X}_{\mathrm{i}}\right)=\frac{1}{1+\mathrm{e}^{-}\left(\beta_{0}+\boldsymbol{\beta}_{1 \mathrm{i}} \mathbf{X}_{\mathrm{i}}\right)}
$$

From Equation (1), the logistic regression to be estimated can be written as:

$$
\operatorname{logit}\left(\text { Brexit }_{\mathrm{i}}\right)=\beta_{0}+\boldsymbol{\beta}_{1 \mathrm{i}} \mathbf{X}_{\mathrm{i}}+\varepsilon_{\mathrm{i}}
$$

where $\operatorname{Pr}\left(\right.$ Brexit $\left._{i}=1\right)$ is the probability of $i^{\text {th }}$ firm reporting Brexit as a major obstacle, $i$ is the number of firms; $i=1, \ldots, n, \mathbf{X}$ is a vector of observed variables that may affect the firm's decisions (see Table 1), $f$ denotes the logistic distribution function, $\varepsilon$ is the standard errors. Since this analysis is focused on the UK, which includes England, Scotland, Wales, and Northern Ireland, which are characterised by different SME support services, geography, and policies, the error term in Equation (2) is therefore clustered for the four nations to control for heteroscedasticity. The average marginal effects are then estimated and reported in the empirical results section.

\section{Data and descriptive statistics}

This study uses the data from the LSBS for $2016^{1}$ which was undertaken between August 2016 and January 2017. It is a large-scale telephone survey of UK small business owners and managers across the UK, commissioned by the Department for Business, Energy and Industrial Strategy (BEIS). The total data of 9,243 SMEs were collected based on a random sample of firms stratified by each UK nation, namely England, Scotland, Wales and Northern Ireland. Table 1 details descriptive statistics. Following the median figure, the majority of SMEs in the UK do not identify Brexit as a major obstacle to their businesses. Only $22 \%(1,996)$ identify that Brexit is a major obstacle to business success, of which $41 \%$ (823) identify that staff recruitment and skill shortages are a major obstacle. Approximately $15 \%$ of these SMEs operate in wholesale and retail sectors, followed by manufacturing and construction sectors $(18.1 \%)$ and professional and science sectors (15.3\%). The majority of SMEs are micro businesses with $32.9 \%$, followed by small-sized businesses $(26.9 \%)$ and medium-sized businesses (14.7\%). More than 20\% are women-led businesses and 29.4\% of the UK SMEs are located in rural areas. Approximately $70 \%$ of UK SMEs are family-owned businesses, while only $16.8 \%$ are sole traders. Approximately $18 \%$ of SMEs have directly imported goods or services in the last 12 months from the EU. While $17.8 \%$ have exported goods or services to the EU.

Considering skill shortages, there are different meanings of skill shortages which can be distinguished between the concepts of skills shortages with skills gaps and recruitment difficulties (Green et al., 1998). In LSBS 2016, skill shortages are recorded in terms of shortage of managerial skills/expertise, shortage of skills within the external labour market, shortage of skills within the existing workplace, and difficulty in recruiting staff. Approximately $32 \%$ $(2,969)$ of the total sample were asked whether their businesses have been affected by skill shortages, and of which $30.4 \%$ report the shortage of managerial skills/expertise in their businesses. Forty-five percent identify that they have been affected by shortage of skills within the existing workplace. Approximately $71.4 \%$ answer that they have been experienced by the shortage of skills within the external labour market. Forty-five percent identify that they have been affected by shortage of skills within the existing workplace. Also, 80.9\% report difficulties in staff recruitment in their businesses.

\footnotetext{
${ }^{1}$ This analysis is derived from LSBS 2016 since the information on "UK exit from the EU as a major obstacle" is only available for 2016 .
} 
Table 1. Descriptive statistics.

\begin{tabular}{|c|c|c|c|c|}
\hline Variable & Obs & Mean & Median & SD \\
\hline $\begin{array}{l}\text { Brexit ( } 1=\text { Firms report UK exit the EU as an obstacle, } \\
0=\text { otherwise) }\end{array}$ & 9,243 & 0.216 & 0 & 0.412 \\
\hline Rural firm ( $1=$ firms located in rural areas, $0=$ otherwise) & 9,243 & 0.294 & 0 & 0.456 \\
\hline Family firm (1=Family-owned businesses, $0=$ otherwise) & 9,147 & 0.695 & 1 & 0.461 \\
\hline $\begin{array}{l}\text { Sole trader (Legal status) ( } 1=\text { sole proprietorship, } \\
0=\text { otherwise) }\end{array}$ & 9,243 & 0.168 & 0 & 0.374 \\
\hline Women-led business ( $1=$ yes, $0=$ otherwise $)$ & 8,814 & 0.207 & 0 & 0.405 \\
\hline Micro business ( $1-9$ employees) ( $1=$ yes, $0=$ otherwise $)$ & 9,243 & 0.329 & 0 & 0.470 \\
\hline $\begin{array}{l}\text { Medium business ( } 50-249 \text { employees) }(1=y e s, \\
0=\text { otherwise) }\end{array}$ & 9,243 & 0.147 & 0 & 0.355 \\
\hline Firm age: $0-5$ years ( $1=y e s, 0=$ otherwise $)$ & 9,243 & 0.125 & 0 & 0.331 \\
\hline Firm age: $20+(1=$ yes, $0=$ otherwise $)$ & 9,243 & 0.522 & 1 & 0.500 \\
\hline $\begin{array}{l}\text { Primary, Production and Construction ( } 1=\mathrm{yes}, \\
0=\text { otherwise) }\end{array}$ & 9,243 & 0.045 & 0 & 0.207 \\
\hline $\begin{array}{l}\text { Retail/Wholesale, Transport and Food services ( } 1=y e s \text {, } \\
0=\text { otherwise) }\end{array}$ & 9,243 & 0.096 & 0 & 0.294 \\
\hline $\begin{array}{l}\text { Business services (Financial/real estate, } \\
\text { Professional/Scientific, Information/communication and } \\
\text { Administrative/support) (1=yes, } 0=\text { otherwise) }\end{array}$ & 9,243 & 0.098 & 0 & 0.298 \\
\hline Business located in London ( $1=y e s, 0=$ otherwise $)$ & 9,243 & 0.108 & 0 & 0.310 \\
\hline $\begin{array}{l}\text { Exporting firms }(1=\text { firms have exported goods/services } \\
\text { to the EU countries, } 0=\text { otherwise) }\end{array}$ & 8,863 & 0.178 & 0 & 0.383 \\
\hline $\begin{array}{l}\text { Importing firms }(1=\text { firms have imported goods/services } \\
\text { from the EU countries, } 0=\text { otherwise) }\end{array}$ & 9,243 & 0.182 & 0 & 0.386 \\
\hline $\begin{array}{l}\text { Shortage of managerial skills/expertise }(1=y e s, \\
0=\text { otherwise })\end{array}$ & 2,969 & 0.314 & 0 & 0.464 \\
\hline $\begin{array}{l}\text { Shortage of skills within the external labour market } \\
(1=y e s, 0=\text { otherwise })\end{array}$ & 2,969 & 0.714 & 1 & 0.452 \\
\hline $\begin{array}{l}\text { Shortage of skills within the existing workplace ( } 1=\text { yes, } \\
0=\text { otherwise) }\end{array}$ & 2,969 & 0.450 & 0 & 0.498 \\
\hline Staff recruitment ( $1=$ yes, $0=$ otherwise) & 2,969 & 0.809 & 1 & 0.393 \\
\hline
\end{tabular}

\section{Empirical results}

Table 2 details the results of the logistic model concerning the probability of a firm who identifies Brexit as a major obstacle. In this analysis, the total sample reduces from 9,243 to only 2,706 observations due to the number of firms reporting skill shortages and missing information on some covariates for these firms. The model appears to perform well correctly predicting the observations with $72.8 \%$, which is relatively high. Also, the Pearson $\chi^{2}$ goodness-of-fit test indicates that the model fits reasonably well ( $p>0.05)$.

The key findings show that SMEs located in rural areas and family-owned businesses are less likely to report Brexit as a major obstacle. This is probably because they are less likely to be knowledge based with a greater international exposure to markets for human capital compared with those located in London and other major cities (Brown et al, 2019). Likewise, sole traders and micro-sized businesses are also less likely to report Brexit as a major obstacle. However, start-up businesses (aged from 0 to 5 years) and firms located in London are more likely to see Brexit as their obstacles. The results of average marginal effects (at mean) (AME) reveal that start-up businesses and firms located in London have a 3.2\% and 10.7\% higher probability to report will be an obstacle for their businesses, respectively. Additionally, Brexit is found to 
Table 2. Probability of Firms affected by Brexit using a Logistic Model and Average Marginal Effect.

\begin{tabular}{|c|c|c|}
\hline Variable & $\begin{array}{r}\text { Coefficient } \\
\text { (SE) }\end{array}$ & $\begin{array}{r}\text { Marginal Effect } \\
(\mathrm{SE}) \\
\end{array}$ \\
\hline Constant & $\begin{array}{r}-1.921 * * * \\
(0.197)\end{array}$ & - \\
\hline Rural firm ( $1=$ yes, $0=$ otherwise $)$ & $\begin{array}{r}-0.114 * * \\
(0.046)\end{array}$ & $\begin{array}{r}-0.022 * * \\
(0.009)\end{array}$ \\
\hline Family firm ( $1=$ yes, $0=$ otherwise $)$ & $\begin{array}{r}-0.143 * * * \\
(0.034)\end{array}$ & $\begin{array}{r}-0.028 * * * \\
(0.007)\end{array}$ \\
\hline Sole trader (Legal status) $(1=$ yes, $0=$ otherwise $)$ & $\begin{array}{r}-0.202^{*} \\
(0.125)\end{array}$ & $\begin{array}{r}-0.039^{*} \\
(0.023)\end{array}$ \\
\hline Women-led business ( $1=$ yes, $0=$ otherwise $)$ & $\begin{array}{r}-0.057 \\
(0.042)\end{array}$ & $\begin{array}{r}-0.011 \\
(0.008)\end{array}$ \\
\hline Micro business ( $1=$ yes, $0=$ otherwise $)$ & $\begin{array}{r}-0.037 * * * \\
(0.011)\end{array}$ & $\begin{array}{r}-0.007 * * * \\
(0.002)\end{array}$ \\
\hline Medium business ( $1=$ yes, $0=$ otherwise) & $\begin{array}{r}0.127 \\
(0.083)\end{array}$ & $\begin{array}{r}0.025 \\
(0.017)\end{array}$ \\
\hline Firm age: $0-5$ ( $1=$ yes, $0=$ otherwise $)$ & $\begin{array}{l}0.170^{*} \\
(0.127)\end{array}$ & $\begin{array}{l}0.032 * \\
(0.025)\end{array}$ \\
\hline Firm age: $20+(1=$ yes, $0=$ otherwise $)$ & $\begin{array}{r}-0.040 \\
(0.051)\end{array}$ & $\begin{array}{r}0.008 \\
(0.010)\end{array}$ \\
\hline $\begin{array}{l}\text { Primary, Production and Construction (1=yes, } \\
0=\text { otherwise) }\end{array}$ & $\begin{array}{r}0.045 \\
(0.133)\end{array}$ & $\begin{array}{r}0.009 \\
(0.026)\end{array}$ \\
\hline $\begin{array}{l}\text { Retail/Wholesale, Transport and Food and } \\
\text { Accommodation services ( } 1=\text { yes, } 0=\text { otherwise) }\end{array}$ & $\begin{array}{r}0.438 * * * \\
(0.098)\end{array}$ & $\begin{array}{r}0.085 * * * \\
(0.021)\end{array}$ \\
\hline $\begin{array}{l}\text { Business services (Financial/real estate, } \\
\text { Professional/Scientific, Information/ communication } \\
\text { and Administrative/support) ( } 1=\text { yes, } 0=\text { otherwise) }\end{array}$ & $\begin{array}{r}0.376^{* * * *} \\
(0.104)\end{array}$ & $\begin{array}{r}0.073 * * * \\
(0.022)\end{array}$ \\
\hline Business located in London ( $1=$ yes, $0=$ otherwise $)$ & $\begin{array}{r}0.553 * * * \\
(0.071)\end{array}$ & $\begin{array}{r}0.107 * * * \\
(0.011)\end{array}$ \\
\hline $\begin{array}{l}\text { Exporting firms ( } 1=\text { firms have exported goods/services } \\
\text { to the EU countries, } 0=\text { otherwise) }\end{array}$ & $\begin{array}{r}0.697 * * * \\
(0.073)\end{array}$ & $\begin{array}{r}0.135 * * * \\
(0.017)\end{array}$ \\
\hline $\begin{array}{l}\text { Importing firms ( } 1=\text { firms have imported goods/services } \\
\text { from the EU countries, } 0=\text { otherwise) }\end{array}$ & $\begin{array}{r}0.698 * * * \\
(0.084)\end{array}$ & $\begin{array}{r}0.135 * * * \\
(0.013)\end{array}$ \\
\hline $\begin{array}{l}\text { Shortage of managerial skills/expertise }(1=y e s, \\
0=\text { otherwise })\end{array}$ & $\begin{array}{r}0.334 * * * \\
(0.059)\end{array}$ & $\begin{array}{r}0.065 * * * \\
(0.012)\end{array}$ \\
\hline $\begin{array}{l}\text { Shortage of skills within the external labour market } \\
\text { (1=yes, } 0=\text { otherwise) }\end{array}$ & $\begin{array}{r}0.197 * * * \\
(0.041)\end{array}$ & $\begin{array}{r}0.038 * * * \\
(0.008)\end{array}$ \\
\hline $\begin{array}{l}\text { Shortage of skills within the existing workplace } \\
(1=\text { yes, } 0=\text { otherwise) }\end{array}$ & $\begin{array}{r}0.028 \\
(0.088)\end{array}$ & $\begin{array}{r}0.005 \\
(0.017)\end{array}$ \\
\hline Staff recruitment ( $1=$ yes, $0=$ otherwise $)$ & $\begin{array}{l}0.223^{*} \\
(0.119)\end{array}$ & $\begin{array}{r}0.043^{*} \\
(0.024)\end{array}$ \\
\hline $\begin{array}{l}\text { Number of Observations } \\
\text { Correctly classified } \\
\text { Probability > chi2 } \\
\text { Pearson chi2(1,859) } \\
\end{array}$ & & $\begin{array}{r}2,706 \\
72.76 \% \\
\mathbf{0 . 6 2 0 9} \\
\mathbf{1 , 8 3 9 . 6 2} \\
\end{array}$ \\
\hline
\end{tabular}

Notes: $*, * *, * * *$ denote significance at $10 \%, 5 \%$ and $1 \%$, SE is standard errors. Since the variables in this analysis are dichotomous, the correlations are tested using "tetrachoric". The highest correlation matrix is 0.39 for the micro businesses and small businesses.

affect many sectors in the UK, especially high-skill sectors. SMEs operating in business services (professional and scientific, financial and real estate, information and communication, and administrative and support sector) and wholesale and retail, transport, and food and 
accommodation services have a $7.5 \%$ and $8.5 \%$ higher probability of firms reporting Brexit as a major obstacle respectively. Also, both exporting and importing SMEs are more likely to be concerned about the impact of Brexit. Firm with both exporting goods/services to the EU and importing from the EU have $13.5 \%$ higher probability of reporting Brexit as an obstacle.

For the potential relationship between Brexit and skill shortages, the AME's result reveal that firms with shortage of managerial skills and expertise have a $6.5 \%$ higher probability to report that Brexit will affect their businesses. Also, SMEs who have been affected shortage of skills within the external labour market have a 3.8\% higher probability to be concerned about Brexit. Likewise, firms reporting difficulty in recruiting staff have a $4.3 \%$ higher probability to report Brexit as a major obstacle. Interestingly, shortage of skills within the existing workplace is not significantly associated with Brexit. This may imply that SMEs in the UK anticipate the effect of Brexit and increase work-based training to increase the skills required in their businesses (FSB, 2017).

\section{Conclusion and recommendations}

This paper examines the potential relationship between Brexit and skill shortages using data of 9,423 UK SMEs from LSBS 2016. More than 20\% of total SMEs identify that Brexit is a major obstacle to their businesses. Using the logistic regression with clustered standard errors, the paper highlight that Brexit can potentially increase skill shortages and difficulty in staff recruitment for SMEs. Firms with a shortage of managerial skills and expertise have the highest probability to report that Brexit will affect their businesses, followed by difficulty in recruiting staff and shortage of skills within the external labour market respectively. The results also reveal that SMEs operating in high-skilled industries such as professional and scientific, food services and accommodation, information and communication (ICT) are more likely to report that Brexit will affect their businesses. If the UK cannot retain a skilled workforce and/or find alternative non-EU sources of high-skilled labour, these industries will face a shortage of labour as they are heavily reliant on EU workers. Since Brexit tends to overturn the free movement of labour, the UK, therefore, should consider the skill-based immigration policy for EU labour and removal of restrictions to recruit skilled workers from the EU for these industries for both shortterm and long-term jobs.

The results also suggest that start-up businesses are more likely to be concerned about the impact of Brexit. Therefore, the UK Government should provide start-up funding and financial support/advice to help SMEs through and beyond Brexit. Without any government support, an increase in start-up failure rates are highly likely and businesses will be at risk and potentially have unclear business plans due to the uncertainty. In addition, exporting and importing SMEs tend to report that Brexit will affect their businesses. Therefore, UK government will urgently need to negotiate a new trading agreement or free trade agreement (FTA) with the EU to stop new tariffs and other trade barriers coming into force after 31 December 2020. At the same time, the UK should put provisions in place to pursue an independent trade policy as well as negotiating FTAs with new potential partners when the UK leaves the Single Market to alleviate any negative consequences of Brexit, such as export and import tariffs, for SMEs who trade internationally. Since Brexit has officially begun, the future of the UK's economic growth as well as social development will therefore depend on the outcomes of the negotiations.

This paper highlights some avenues for further research. Firstly, this paper only focuses on the empirical study based on the information of the secondary data. Therefore, given the quantitative nature, qualitative analysis, such in-depth interviews, is recommended to gain deeper understanding of concerns that SMEs have about Brexit and skill shortages. Secondly, due to data limitations, future research would benefit from longitudinal data analysis to better understand the resilience of SMEs to the long-term impact of Brexit. 


\section{Acknowledgments}

The author is grateful to the Department for Business, Energy and Industrial Strategy (BEIS) for data which is available upon request at UK Data Service: www.ukdataservice.ac.uk.

\section{References}

BEIS (2018) Statistical Release, Department for Business, Energy and Industrial Strategy, available via https://assets.publishing.service.gov.uk/government/uploads/system/uploads/attachment_data/file/746599/OFFICIAL_SENSITIVE_-_BPE_2018__statistical_release_FINAL_FINAL.pdf (access 15 October 2018).

Brown, R., Liñares-Zegarra, J. and Wilson, J. O. S. (2019) The (potential) impact of Brexit on UK SMEs: regional evidence and public policy implications, Regional Studies, 53(5), 761770.

FBS (2017) Learning the ropes - skills and training in small businesses, the Federation of Small Businesses, available via https://www.fsb.org.uk/resources-page/skills-and-training-reportpdf.html (accessed: 3 March 2020).

Green, F., Machin, S., and Wilkinson, D. (1998) The meaning and determinants of skills shortages, Oxford Bulletin of Economics and Statistics, 60(2), 165-187.

McCollum, D., and Findlay, A. (2015) Flexible' workers for 'flexible' jobs? The labour market function of A8 migrant labour in the UK, Work, Employment and Society, 29(3), 427-443.

Miller, V. (2016) Brexit: Impact across policy areas, Briefing Paper No. 07213, London: House of Commons.

ONS (2018) Migration Statistics Quarterly Report: November 2018, available via https://www.ons.gov.uk/peoplepopulationandcommunity/populationandmigration/internationalmigration/bulletins/migrationstatisticsquarterlyreport/november2018 (accessed 9 December 2018).

Portes, J., and Forte, G. (2017) The economic impact of Brexit-induced reductions in migration, Oxford Review of Economic Policy, 33, S31-S44.

The Edge Foundation (2018) Skills Shortages in the UK Economy, Edge Bulletin, 2, available via http://www.edge.co.uk/publications/digital-skills-shortages-in-the-uk-economy (accessed 1 October 2018).

The Edge Foundation (2019) Skills Shortages in the UK Economy, Edge Bulletin, 4, available via https://www.edge.co.uk/sites/default/files/publications/skills_shortage_bulletin_4_web1.pdf (accessed 3 March 2020). 